\title{
Advantages and disadvantages of the flow construction
}

\author{
Jian Liu \\ Chongqing Technology and Business Institute, Chongqing 400052, China; \\ 635629601@qq.com
}

\section{Keywords: flow construction, construction period, intermittence}

Abstract. By studying the organization mode of the flow construction, this research analyzed the advantages and disadvantages of the flow construction. Meanwhile, this research proposed the construction methods applicable to the actual engineering, and explained the methods by using the project case.

\section{Introduction}

During the construction of the engineering projects, the construction object is usually divided into several similar construction sections, that is, the whole construction process is divided into several different processes. Meanwhile, the professional construction teams are established for each construction process to build different construction sections successively according to the sequence of the construction technology. The various construction progresses in different construction sections are required to be synchronous and overlapped as possible. This is the so called flow construction. the flow construction is endowed with the following advantages:The working faces are utilized in the construction process as possible, and the construction period is short; The construction teams have realized the specialized production, accompanying with the improved labor productivity and engineering quality. It is also conducive to enhancing the technical level and improving the production tools; The professional teams are able to operate successively, and the construction times of the professional teams of adjacent construction processes have realized a large degree of lap joint; The amount of the resources invested in the unit time is characterized by regularity and proportionality, which is convenient for the supply of the organization resources; It provides conditions for the reasonable construction and scientific management.

Therefore, flow construction is generally a very scientific and reasonable construction mode, and thus widely applied in the engineering practices. As is well known, the purpose of the flow construction is to reasonably and scientifically arrange the production factors during the construction process of buildings, so as to realize the lowest consumption of the labor resources and the shortest construction period. By doing so, the construction tasks can be fulfilled while ensuring both the quality and quantity, so that enterprises can acquire the maximum economic benefit. the construction processes of each construction section are all continuous. However, such arrangement also presents drawbacks: some working faces are not fully utilized.

\section{Case of the partially intermittent flow constructio}

The five-layered office building of a company with the building area being $2300 \mathrm{~m}^{2}$ was applied as the project case. The foundation of the building was the strip foundation of reinforced concrete (RC), and the main project was the frame structure of the cast-in-place concrete. The fitment project included the installation of the aluminum alloy windows and plywood doors. Pink wall tiles were adopted on the exterior wall, while high-quality coatings were painted on the intermediately plastered interior wall. The roof was constructed using the roof slab made of the cast-in-place fine stone and RC. The GPFS-1 polyurethane waterproof coating and the overhead heat insulation layer were utilized as the waterproof and heat insulation layers, respectively. The flow construction was adopted in this building, and the amount of labor is demonstrated in table 1. 
table 1 Schedule of the amount of labor for the five-layered office building

\begin{tabular}{|c|c|c|}
\hline Serial & The names of each process & the amount of labor/( work day) \\
\hline & Foundation engineering & \\
\hline 1 & Excavation of the foundation trench & 224 \\
\hline 2 & Concrete cushion & 16 \\
\hline 3 & foundational reinforcement binding & 64 \\
\hline 4 & Foundational concrete & 130 \\
\hline 5 & Plain concrete based wall foundation & 70 \\
\hline \multirow[t]{2}{*}{6} & Backfill & 64 \\
\hline & Main project & \\
\hline 7 & Scaffold & 112 \\
\hline 8 & Rebars in column & 100 \\
\hline 9 & The templates of the columns, beams and & 1200 \\
\hline 10 & plates & 400 \\
\hline 11 & Concrete column & 400 \\
\hline 12 & Beams and backstraps & 900 \\
\hline 13 & Beams and concrete plates & 200 \\
\hline \multirow[t]{2}{*}{14} & $\begin{array}{l}\text { Form removal } \\
\text { Walling }\end{array}$ & 900 \\
\hline & Roofing project & \\
\hline 15 & Waterproof layer of the roof & 62 \\
\hline \multirow[t]{2}{*}{16} & Heat insulation layer of the roof & 36 \\
\hline & Decoration and fitment project & \\
\hline 17 & The cement mortars on the floor surface and & 600 \\
\hline 18 & stairs & 800 \\
\hline 19 & intermediately plastered ceiling and wall & 100 \\
\hline 20 & Aluminum alloy window & 58 \\
\hline 21 & Plywood door & 60 \\
\hline 22 & Ceiling and coatings & 60 \\
\hline 23 & Paint & 480 \\
\hline 24 & External wall tiles & \\
\hline 25 & Installation of sanitary equipments & \\
\hline 26 & $\begin{array}{l}\text { Installation of electrical equipments } \\
\text { Outdoor engineering }\end{array}$ & \\
\hline
\end{tabular}

The flow mode was applied on the aforementioned projects in this research. To begin with, these projects were divided into several sub-projects, namely, the foundation, main, roofing, decoration and fitment projects according to the structural position. Afterwards, the flow construction was performed on each sub-project. Finally, the various sub-projects were overlapped according to the construction sequence.

The construction of the foundation project

The foundation project included six construction processes such as the excavation of the foundation trench, the concrete cushion and so on. Concerning the fact that the amount of labor in the foundational concrete cushion was small, the construction process of the concrete cushion was combined with the excavation process. Meanwhile, since the constructions of the foundational concrete and the plain concrete based wall foundation belonged to the same type of work, the two processes were combined as well.

The foundation project contained merely four construction processes $(n=4)$ after the combination, which were performed with the same beat in the flow construction later. Since this project covered an area of approximately $800 \mathrm{~m} 2$, it was divided into two construction sections $(m=2)$ in consideration of the working faces. The numbers of workers arranged for excavating the foundation trench, binding the foundational reinforcements, and preparing the foundational concrete and plain concrete based wall foundation were 30, 8, and 25, respectively. Meanwhile, 8 workers were arranged to backfill the foundational. The single-shift system was adopted by these four processes. 
Then, the flowing beat was calculated as $t_{d}=4(d)$. Therefore, the construction period of the foundation project is expressed as:

$$
\begin{aligned}
T_{L} & =(m+n-1) t_{i}+\sum t_{j}-\sum t_{d} \\
& =(2+4-1) \times 4+2-0=22(d)
\end{aligned}
$$

Main project

The main projects contained 8 sub-projects including the installations of the scaffolds, the binding of the rebars in columns, the installation of the templates of the columns, beams and plates, the binding of the beams and backstraps, the casting of concrete columns, beams and concrete plates, form removal, and walling. However, the installation project of the scaffolds was carried out alone without being divided into layers and sections, and synchronously with the main project. Therefore, merely 7 sub-projects were considered in this project, namely, $n=7$.

In order to shorten the construction period, the intermittent flow construction was adopted by part of the sub-projects of the main project. The intermittent construction teams were uniformly arranged with other sites to organize the great flow process. The flowing beat and construction period were calculated as follows:

(1) The rebars in columns were bound by a construction team of 10 workers for 100 work days. Meanwhile, the single-shift system was adopted, and the number of the construction sections was $m=2 \times 5$. Then, the flowing beat can be calculated as follows:

$$
t_{1}=\frac{100}{10 \times 2 \times 5}=1(d)
$$

The installation of the templates of the columns, beams and plates was realized by 20 worker for 1200 work days. The single-shift system was adopted, and the number of the construction sections was $m=2 \times 5$. The flowing beat is formulated as follows:

$$
t_{2}=\frac{1200}{20 \times 2 \times 5}=6(d)
$$

(3) The concrete columns were cast by a team of 20 for 400 work days. The two-shift system was applied here, with the number of the construction sections being $m=2 \times 5$. The flowing beat is given:

$$
t_{3}=\frac{400}{20 \times 2 \times 5 \times 2}=1(d)
$$

(4) A construction team of 20 worked for 400 work days to bind the beams and backstraps. This project adopted the one-shift system, and the number of the construction sections was $m=2 \times 5$. The flowing beat is expressed as follows:

$$
t_{4}=\frac{400}{20 \times 2 \times 5}=2(d)
$$

(5) The beams and concrete plates were cast by a construction team of 30 working for three shifts of 900 work days. With the number of the construction sections being $m=2 \times 5$, the flowing beat is calculated:

$$
t_{5}=\frac{900}{30 \times 2 \times 5 \times 3}=1(d)
$$

(6) Ten workers were allocated to remove the templates of the columns, beams and plates. The process was finished in 200 work days with one shift. The number of the construction sections was $m=2 \times 5$. The flowing beat is given as:

$$
t_{6}=\frac{200}{10 \times 2 \times 5}=2(d)
$$

In this project, as the templates of the columns, beams and plates were removed all together, they were considered as a single construction process, that is to say, the templates were removed 12 days after the casting of the beams and concrete plates. 
(7) As to the amount of labor for walling, the project was achieved by a team of 30 worked for 900 work days with one shift. The flowing beat is calculated using the following formula with the number of the construction sections being $m=2 \times 5$.

$$
t_{7}=\frac{900}{30 \times 2 \times 5}=3(d)
$$

The construction period of the main project is calculated as follows:

Since the installation of the templates of the columns, beams and plates in the main project required the greatest amount of labor and the longest flowing beat, the installation of the templates was conducted continuously. While, the intermittent construction was adopted for other construction processes which presented small amount of labor and flowing beat. Therefore, the construction period of this main project was calculated utilizing the analytical calculation method instead of the formula used to calculate the construction period of the ordinary flow construction. That is to say, the construction period of this main project can be calculated by combining the sum of the time for installing the ten sections $(m=2 \times 5)$ of templates of the columns, beams and plates with the flowing beats of other processes and the maintenance time:

$$
\begin{aligned}
T_{L} & =t_{2} \times 10+t_{1}+t_{3}+t_{4}+t_{5} \times 2+t+t_{6}+t_{7} \times 2 \\
& =6 \times 10+1+1+2+1 \times 2+12+2+3 \times 2=86(d)
\end{aligned}
$$

Where, the first item that multiplies 2 represents the time spent on the continuous concrete casting of the roof, and the second item indicates the time taken for the continuous construction of the last layer of bricks.

\section{Conclusions}

The appropriate selection of the flow construction modes depends on the actual condition. In engineering practices, construction enterprises can adopt the intermittent flow construction in part of the processes at the right moment according to circumstances. While organizing the flow construction, enterprises can pay more attention to the arrangement of one or several main construction processes, namely, the construction processes with great engineering quantity and duration, so as to carry out the continuous construction. Taking the installation process of the templates of the columns, beams and plates in this case for an example, it presented the greatest amount of labor and longest flowing beat. Intermittent construction can be applied to the construction processes with small engineering quantity and duration. Thereby, the various construction processes can realize the maximum degree of lap joint, so as to shorten the construction period.

\section{References}

[1] Yi Jun, Xia Ying, et al. Organization and Schedule Management for Building Construction. Chemical Industry Press, Beijing, 2006.

[2] Li Yufen and Feng Ning. Construction Project Management. China Machine Press, Beijing, 2008.

[3] Fan Hongyan. Construction Project Management. Peking University Press, Beijing, 2008.

[4] Zhao Yanhui. Introduction to the Management of the Site Construction of the Construction Engineering. China Electric Power Press, Beijing, 2007. 